Article

\title{
Drought Enhances the Role of Competition in Mediating the Relationship between Tree Growth and Climate in Semi-Arid Areas of Northwest China
}

\author{
Kanglong Lu ${ }^{1,2} \mathbb{C}$, Ning Chen ${ }^{1,2}$, Cankun Zhang ${ }^{1,2}$, Xiaoxue Dong ${ }^{1,2}$ and Changming Zhao ${ }^{1,2, *}$ \\ 1 State Key Laboratory of Grassland Agro-Ecosystems, School of Life Sciences, Lanzhou University, \\ Lanzhou 730000, China; lukl13@lzu.edu.cn (K.L.); cn@lzu.edn.cn (N.C.); zhangck14@lzu.edu.cn (C.Z.); \\ dongxx18@lzu.edu.cn (X.D.) \\ 2 Yuzhong Mountain Ecosystem Field Observation and Research Station, Lanzhou University, No. 222, \\ Tianshui South Road, Lanzhou 730000, China \\ * Correspondence: zhaochm@lzu.edu.cn; Tel.: +86-0931-8912551; Fax: +86-0931-89125517
}

Received: 23 July 2019; Accepted: 9 September 2019; Published: 14 September 2019

check for updates

\begin{abstract}
Climate variability can exert a powerful impact on biotic competition, but past studies have focused largely on short-lived species, with a lack of attention to long-lived species such as trees. Therefore, there is a need to evaluate how competition regulates the climate-growth relationship in mature trees. We sampled the dominant tree species, Picea wilsonii Mast., on Xinglong Mountain, China, and studied the above issues by analyzing the relationship between tree radial growth, precipitation, and competition. In relatively wet years (precipitation $>$ average), there was no significant difference in climate sensitivity between different competition classes. However, trees suffering from highly competitive stress were more sensitive to climate variability in all years, and particularly in the subset of years that was relatively drought (precipitation $<$ average). These results suggest that competition enhances its ability to regulate tree growth response to climate variability in adverse weather conditions. Competition for resources between trees was asymmetrical, and an increase in height could give trees a disproportionate benefit. Thus, at trunk-level, both basal area incremental growth and intrinsic water-use efficiency of trees subjected to low competitive stress were significantly higher than trees that are subjected to highly competitive stress. Although the intrinsic water-use efficiency of trees under highly competitive stress increased more rapidly as the drought level increases, this did not change the fact that the radial growth of them declined more. Our research is valuable for the development of individual-tree growth models and advances our understanding for forest management under global climate change.
\end{abstract}

Keywords: competition; climate-growth relationship; tree rings; resources utilization; allometry

\section{Introduction}

Climate variability has a relevant impact on biotic interactions [1-3]. This is supported by the dominant conceptual models like the stress-gradient hypothesis (SGH) [4] and competition-stress-ruderal (CSR) plant strategy theory [5]. The processes of these models indicate that competitive interactions will strongly affect plant growth under beneficial climatic conditions, but that the overall effect of competition, in adverse weather conditions, should be less significant. That is because, under beneficial climatic conditions, plants are able to acquire resources quickly, and the preferential possession of resources gives plants an advantage for subsequent survival $[5,6]$. In contrast, under adverse weather conditions (e.g., drought years), a plant's rapid access to resources is limited and stress tolerance is more important than competition for resources [7]. The initial application of SGH was mainly in an 
interspecific level, but later studies have shown that this theory is equally applicable to the intraspecific level $[8,9]$.

Carnwath and Nelson (2016) reviewed studies addressing the relative importance of competition along a gradient of abiotic stress [10]. They concluded that previous studies have mainly focused on short-lived species, such as herbs, rather than long-lived species, such as trees. However, an extended lifespan may confer different characteristics (e.g., strong phenotypic plasticity) on plant species, such that they can significantly alter their resource acquisition and stress tolerance capability in response to environmental changes $[11,12]$. These changes can affect the relationships between climate sensitivity and competition among mature trees $[13,14]$. Given that trees that die as a result of environmental stress (e.g., drought) are more sensitive to climate changes (i.e., a higher degree of coupling of stem growth to climate) [15-18], understanding how competition mediate the climate-growth relationship is important in order to predict the response of tree growth under climate change.

Some studies have suggested that trees subjected to low levels of competitive stress are more sensitive to climate variability [19-21]. However, other studies support that trees subjected to high level of competitive stress have a more sensitive response to climate variability [22-24]. No consistent conclusions have been drawn about this issue. We believe that the sensitivity of tree growth to precipitation may vary at different precipitation levels. The difference in the above results is probably due to the large differences in precipitation conditions at the study sites (from the continental Mediterranean climate to the tropical rainy climate). In addition, all of the above studies only analyzed the response of tree growth to stress changes in all years, and did not further explore its subsets (e.g., relatively dry and wet years). Therefore, it is impossible to discuss the sensitivity of trees under different precipitation levels on the same research site. However, we maintain that the analysis of different precipitation levels in the same location contributes to an in-depth understanding of the competition-regulating growth-precipitation relationships.

Trees compete fiercely for limited resources [25]. An increase in height can provide trees disproportionately greater benefits; taller trees (usually large trees, low competitive stress) can restrict the light of shorter trees (usually small trees, high competitive stress) with their advantage of height, so the amount of resources obtainable by shorter trees is far less than the proportion of their biomass [26,27]. However, the lower canopy is sheltered by the higher canopy and is less affected by external environmental stress. Hence, the rate of water transpiration by shorter trees is much lower than that of the taller trees, enabling shorter trees to grow better than taller trees under water stress in drought years [28]. Additionally, as tree height increases, the upward transportation of water is highly restricted and thus taller trees are at a disadvantage compared with shorter trees $[29,30]$. Therefore, the response of trees with different competitive ability (shorter and taller trees) to climate depends on the trade-off between carbon fixation and water use.

To quantify carbon-fixation ability, the sum of photosynthesis by all leaves is generally expected to be the dominant process. Although the overall photosynthetic capacity is difficult to measure directly, the trunk, as a secondary indicator of tree growth, can provide a good indication of it [31]. For plant water-use efficiency of whole trees, data can be obtained by measuring carbon stable isotopes in stems [32]. In addition, the stem records information on the response of tree growth to environmental factors on a longer time scale [33] and also preserves the information of biotic interactions $[34,35]$. Accordingly, tree rings are ideal materials for studying the competition-regulating climate-growth relationships.

In semi-arid regions of northwest China, relatively constant precipitation is accompanied by an increase in temperature $[36,37]$. Therefore, the limitations of drought on tree growth are more obvious. Water shortage provides a good experimental environment, as precipitation becomes a major factor limiting tree growth, simplifying the analysis of the complex response of tree growth to varied climatic factors [38]. In this study, we sampled the dominant species, Picea wilsonii Mast., in a natural stand on Xinglong Mountain, China, and assessed the relationships between tree growth, climate variability and intraspecific competition. At the levels of stems, we compared the tree radial growth and intrinsic 
water use efficiency of different competition-level trees to reveal some of the physiological mechanisms behind the relationships. We hypothesized that, in adverse conditions, the ability of competition in mediating the climate-growth relationship is important and there should have a significant difference in climate sensitivity between trees of different competition classes.

\section{Materials and Methods}

\subsection{Study Site and Climatic Data}

The National Nature Reserve of Xinglong Mountain (longitude: $103^{\circ} 50^{\prime} \mathrm{W}$ to $104^{\circ} 10^{\prime} \mathrm{W}$; latitude: $35^{\circ} 38^{\prime} \mathrm{N}$ to $35^{\circ} 58^{\prime} \mathrm{N}$; elevation: $2000 \mathrm{~m}$ to $3600 \mathrm{~m}$ ), is in a semi-arid region of northwest China. The region has a continental climate, with precipitation and high temperatures occurring during the same season. In the last 60 years, the mean annual temperature of the reserve has increased from $6.81{ }^{\circ} \mathrm{C}$ to $7.39{ }^{\circ} \mathrm{C}$, mean annual precipitation has decreased from $421 \mathrm{~mm}$ to $378 \mathrm{~mm}$. This aggravated the negative impact of drought on tree growth. We evaluated the climate factors (such as temperature, precipitation, or the Palmer Drought Severity Index) affecting trees and found that precipitation is the main climate factor that influences the growth of P. wilsonii [38]. Therefore, in the following analysis, we only studied the response of tree growth to precipitation.

Precipitation data were derived from the China meteorological data-sharing service. We selected the Meteorological Station (latitude: $35^{\circ} 52^{\prime} \mathrm{N}$; longitude: $104^{\circ} 09^{\prime} \mathrm{E}$; elevation: $1917 \mathrm{~m}$ ) in the county of Yuzhong, which is $5 \mathrm{~km}$ away from the reserve, as the source of the data. Data of atmospheric carbon dioxide concentration after 1997 were acquired from the Earth System Research Laboratory (ftp://aftp.cmdl.noaa.gov/data/trace_gases/). Data of atmospheric carbon dioxide concentration before 1997 were obtained from McCarroll and Loader (2004) [39].

\subsection{Field Survey and Individual Tree Competition Index}

Sampling site has an average elevation of $2372 \mathrm{~m}$, and the vegetation type is $P$. wilsonii pure forest. We selected nine plots in the area, in shady slopes. The size of the plots was $900 \mathrm{~m}^{2}(30 \mathrm{~m}$ by $30 \mathrm{~m})$ except for one that was $800 \mathrm{~m}^{2}$ (20 m by $40 \mathrm{~m}$ ). In order to measure the distance between the subject tree and the competitor tree, a total station was used to locate all the trees in the plot to generate a spatial distribution map. Tree diameter at breast height $(\mathrm{DBH})($ at a height of $1.3 \mathrm{~m})$ was measured with a tapeline. Tree height and crown width were measured using a Vertex Laser 5 (Haglöf Sweden, Långsele, Sweden). Here, the assessment of the canopy was simplified to the length of the horizontal projection along the north-south direction and the east-west direction.

Under the site of uneven age, individual trees undergo a great difference in competition, which depends not only on the size of the subject tree, but also on the size and distance of the competitor trees around it. Considering these situations, we chose an individual tree competition model that depends on the size of the subject tree and competitor tree and the distance between them [40]:

$$
C I_{i}=\sum_{j=1}^{n}\left(D_{j} / D_{i}\right) /(D I S T)_{i j}
$$

where $C I_{i}$ is the individual tree competition index $(C I)$ of the subject tree $i$. The larger the $C I$ value, the greater the competitive stress of the subject tree. $D_{i}$ is the DBH of the subject tree $i$, and $D_{j}$ refers to the DBH of the $j$ th competitor tree around the subject tree $(j=1,2, \ldots, n)$. DIST $i j$ is the spatial distance between the $i$ th subject tree and the $j$ th competitor tree around it, and $n$ is the total number of individuals of all competitor trees around a certain subject tree.

Crown size and shade of the trees were taken into account in the selection of competitor trees around the subject tree. We considered influencing radius from $3 \mathrm{~m}$ to $10 \mathrm{~m}$ and found that the change of $C I$ after $5 \mathrm{~m}$ is less pronounced. Therefore, we used the trees within the radius of $5 \mathrm{~m}$ around the subject tree as the competitor trees. To prevent misleading of the research results due to 
underestimation of the $C I$ value of the trees on the boundary, we only considered the trees within $5 \mathrm{~m}$ from the plot boundary as the competitor trees and did not regard them as the subject tree to calculate its $C I$.

\subsection{Field Sampling and Dendrochronological Methods}

Tree core sampling ( $5 \mathrm{~mm}$ in diameter at a height of $1.3 \mathrm{~m}$ ) was carried out with an increment borer, and tree ring width was measured using a Lintab 5 tree-ring measurement station (RINNTECH, Heidelberg, Germany). For a tree with multiple tree cores, we used the weighted average method to calculate its average series. This method can remove the impact of extreme singular values on the analysis results. We also did not further consider trees that did not pass the cross-dating. Given that the trees we studied here should not only pass the cross-dating (to ensure the study can be analyzed on long-term scales), but also have a competitive index (to evaluate the level of competitive stress the trees are experiencing), 82 tree-ring series, ultimately, were thought suitable for subsequent analysis. We conducted field sampling in the autumn of 2015 and completed the analysis in 2016 [38].

Tree-ring width shows a prominent trend to change with both the tree size and tree age, therefore, to more accurately evaluate the climate-growth relationship, it is essential to detrend the raw data. We processed the original sequence of tree-ring widths with a spline function to obtain a standardized tree growth index (ring width index $(R W I)$ ). RWI was used to calculate the correlation between tree growth and climate (precipitation). Basal area increment (BAI) eliminates the tendency of tree radial growth to vary with the size and age of the tree while reserves the information of climatic factors [34]. It can better reflect the growth of trees than unprocessed tree-ring width series [41]. Thus, we also used $B A I$ to represent tree growth. The transformation forms from raw data to RWI and BAI were as follows.

$$
R W I=W_{\text {original }} / W_{\text {spline }}
$$

where $W_{\text {original }}$ is the original tree ring width and $W_{\text {spline }}$ is the detrended width processed by spline function.

$$
B A I=\pi\left(R_{n}-R_{n-1}\right)^{2}(n=1,2,3 \ldots)
$$

$R$ represents the inner tree-ring radius. Subscript $n$ denotes the year that the tree ring grows.

All data processing was undertaken using $R$ version 3.3.1 [42]. The bi-weight method used to calculate the mean values, cross-dating, and the calculation of $R W I$ were completed using the Dendrochronology Program Library in $R$ [43].

\subsection{Intrinsic Water-Use Efficiency}

\subsubsection{Tree-Ring Carbon Isotopes}

We sampled nine tree cores $(10 \mathrm{~mm}$ in diameter at a height of $1.3 \mathrm{~m})$ for carbon isotope measurement and divided them into three groups according to the following standards: Low competition-level trees (CI obviously larger than average, dominant individuals with little competitors around it), medium competition-level trees (CI approximately equal to average, with a moderate number of competitors around it), and high competition-level trees (CI obviously less than average, inferior individuals with many competitors around it). After cross-dating, three low competition-level trees, three medium competition-level trees, and three high competition-level trees were obtained for further analysis. Under a stereoscope, we used a scalpel to separate the tree rings of different years. Samples of the same year within one group were then mixed and comminuted. Pulverized samples were used for the extraction of alpha-cellulose (Please refer to Brendel et al. (2000), Evans and Schrag (2004), and Gaudinski et al. (2005) for the extraction method in details) [44-46]. Finally, determination of carbon stable isotope $\left(\delta^{13} C\right.$, the reference standard is Vienna Pee Dee Belemnite) was completed in a carbon dioxide isotope analyzer connected with a Vario TOC elemental analyzer (Los Gatos Research, San Francisco, CA, USA; Elementar Analysensysteme GmbH, Hanau, Germany). We performed six 
measurements on each mixed sample and then used the bi-weight method to calculate the average of these six values. The sampling work was completed in 2016, while the measurement and data analysis were completed in 2017 [38].

\subsubsection{Conversion of Carbon Isotope to Intrinsic Water-Use Efficiency}

Tree-ring $\delta^{13} \mathrm{C}$ reserved the trend of atmospheric $\delta^{13} \mathrm{C}$ over the last 60 years [47]. Therefore, the data was detrended [48]:

$$
\Delta^{13} C=\left(\delta^{13} C_{\text {atmosphere }}-\delta^{13} C_{\text {plant }}\right) /\left[1+\left(\delta^{13} C_{\text {plant }} / 1000\right)\right],
$$

where $\delta^{13} C_{\text {atmosphere }}$ and $\delta^{13} C_{\text {plant }}$ represent the carbon isotope values of the carbon dioxide in the atmosphere and the untreated carbon isotopes for the trees. Data of $\delta^{13} C_{a t m o s p h e r e ~}$ after 1997 were obtained from the Earth System Research Laboratory (ftp://aftp.cmdl.noaa.gov/data/trace_gases/). Data of $\delta^{13} C_{\text {atmosphere }}$ before 1997 were acquired from McCarroll and Loader (2004) [39]. We then used the following two formulas to calculate intrinsic water-use efficiency (iWUE) [49]:

$$
\Delta^{13} C=m+(n-m) /\left(C_{\text {intercellular }} / C_{\text {atmosphere }}\right)
$$

where $m(4.4 \%)$ indicates the fractionation coefficient of carbon isotopes during stomatal diffusion, and $n(27.0 \%$ o denotes the fractionation coefficient of carbon isotopes related to carboxylation by Rubisco. $C_{\text {intercellular }}$ represents the intercellular carbon dioxide concentration, while $C_{\text {atmosphere }}$ represents the carbon dioxide concentration in atmosphere.

$$
i W U E=A / g_{\text {stomatal }}=\left(C_{\text {atmosphere }}-C_{\text {intercellular }}\right) / 1.6
$$

where 1.6 represents the rate that carbon dioxide and water diffuse through the atmosphere. $A$ indicates the photosynthesis, and $g_{\text {stomatal }}$ means the stomatal conductance.

\subsection{Data Analysis}

To evaluate the effects of competition and precipitation on tree growth more accurately, we developed a linear mixed-effects model (LMM) $(n=5002 ; 82$ subject trees with 61 observations each). We added tree identity and year as random effect to the model to minimize the effects of irrelevant variables on the results of the analysis. Only $C I$, precipitation, and their interaction were preserved in the fixed effect. Additionally, the temporal correlation of model residuals was explained by the first-order autocorrelation structure. To analyze how competition affects the sensitivity of tree growth to climate response, we performed a regression analysis between CI and correlation coefficients (Pearson correlation coefficient between RWI and precipitation during the last 61 years). In addition, we divided competition into groups to further analyze the reasons why competition regulates tree growth in response to climate sensitivity. We sorted all the trees by CI value and then divided them into three groups on average. There were 27 low competition-level trees, 28 medium competition-level trees, and 27 high competition-level trees. We first calculated the Pearson correlation coefficient between $R W I$ and precipitation during the last 61 years for low, medium, and high competition-level trees. Then, depending on the amount of precipitation during the time period, the years were divided into relatively "dry" (precipitation < average value of $387 \mathrm{~mm}$ ) and "wet" (precipitation > average value of $387 \mathrm{~mm}$ ) years. For the dry and wet years, the Pearson correlations between RWI and precipitation of low, medium, and high competition-level trees were calculated separately. Similarly, we also performed a regression analysis on the relationship between $C I$ and correlation coefficients in dry and wet years. The sensitivity of tree growth response to climate was judged according to the correlation coefficients. A higher coefficient meant tree growth was more sensitive to climate variability. Considering the hysteresis of tree growth response to climate [38], both the LMM and the correlation analysis used precipitation of the previous year and tree growth of the current year. These analyses were carried out 
in the R environment [42]; the construction of the LMM used the nlme package, and the difference comparison used the Tukey HSD method with the anova function.

The comparison of tree radial growth and water use efficiency was performed at the trunk-level. We used the $B A I$ to indicate tree radial growth. The difference in water use efficiency was compared using $i W U E$. We not only compared the BAI and $i W U E$ of different competition-level trees in all years, but also in dry and wet years. The significance of any difference was determined using the Tukey HSD method with the anova function in R [42].

We found that tree height is closely related to the competitiveness of trees. Consequently, we also analyzed the allometric growth between tree height, crown area, and BAI. The crown area calculation was simplified as the product of the length of the north-south and east-west measurements. In addition, the BAI and $i W U E$ of the trees varied with the precipitation gradient. We examined the difference in these changes between the low, medium, and high competition-level trees. When analyzing the relationship between precipitation and tree growth, we used the precipitation of the previous year and the tree growth of the current year, while the analyses of the relationship between precipitation and $i W U E$ both used the current-year data. BAI, iWUE, and precipitation data were all based on 10 -year moving averages to minimize inter-annual variability. The test for allometric growth and the difference in allometric growth equation were performed in R [42] using the standardized major axis (SMA) estimation and testing features in the Standardized Major Axis Estimation and Testing Routines package (smatr). The slope of the regression equation provided the allometric growth index. A slope not equal to one meant that there was allometric growth, and different slopes suggested diverse allometric growth patterns.

\section{Results}

From 1955 to 2014, precipitation in the study area ranged from $231 \mathrm{~mm}$ to $607 \mathrm{~mm}$, with a mean value of $387 \mathrm{~mm}$ (Figure 1a). During this time, there were 30 relatively "dry" years (precipitation < average) and 31 relatively "wet" years (precipitation > average). The mean BAI for low, medium, and high competition-level trees was $11.24 \mathrm{~cm}^{2}$ year-1 $(\mathrm{SE}=0.38), 6.14 \mathrm{~cm}^{2}$ year $^{-1}(\mathrm{SE}=0.27)$, and $2.65 \mathrm{~cm}^{2}$ year $^{-1}(\mathrm{SE}=0.16)$, respectively (Figure $1 \mathrm{~d}$ ). Additionally, regression analysis showed that $\operatorname{DBH}(R=0.87, p<0.001)$, age $(R=0.37, p=0.01)$, and height $(R=0.80, p<0.001)$ of the trees decreased, significantly with increasing $C I$ (Appendix A Figure A1a-c). Table 1 shows the mean $C I$, height, DBH, age, and crown area for trees with different levels of competition.

Table 1. Number of trees, average competition index (CI), height, diameter at breast height (DBH), age at breast height and crown area for different competition groups of trees.

\begin{tabular}{ccccccc}
\hline $\begin{array}{c}\text { Competition } \\
\text { Groups }\end{array}$ & $\boldsymbol{C I}$ & $\begin{array}{c}\text { Tree Height } \\
\mathbf{( m )}\end{array}$ & DBH (cm) & Age & $\begin{array}{c}\text { Crown Area } \\
\left(\mathbf{m}^{\mathbf{2}}\right)\end{array}$ & No. of Trees \\
\hline Low & $0.34(0.03)$ & $26.94(0.72)$ & $45.51(1.69)$ & $118(3)$ & $62.19(5.72)$ & 27 \\
Medium & $1.00(0.04)$ & $24.70(0.70)$ & $36.50(1.25)$ & $115(2)$ & $41.23(3.98)$ & 28 \\
High & $2.48(0.12)$ & $19.01(0.50)$ & $22.61(0.92)$ & $106(1)$ & $14.15(2.05)$ & 27 \\
\hline
\end{tabular}

Numbers in parentheses are standard errors.

The LMM results showed that precipitation $(p<0.001)$ positively impacted tree growth, while $C I$ $(p<0.001)$ negatively impacted tree growth (Table 2$)$. In addition, the interaction $(p<0.001)$ between $C I$ and precipitation had a positive effect on tree growth (Table 2). This indicated that the effect of competition on tree growth varies with precipitation level. The results of linear regression showed that, in all years ( $p=0.023$; Figure 2a) and "dry" years ( $p=0.022$; Figure 2c), the correlation between RWI and precipitation increased significantly with the increase of $C I$, while in "wet" years, the correlation showed a slight decline trend but was not significant $(p=0.176$; Figure $2 c)$. The correlation analysis indicated that there were significant inter-competition group differences in the correlation $(r)$ (i.e., climate sensitivity) between precipitation and tree growth across all years (Figure 2b), with a little lower 
$r$ for low than for high competition-level trees ( $p=0.048$; mean $=0.32$ and 0.36 , respectively). The trend for years in which precipitation < average (dry years) was similar to that of all years: Differences between the competition groups (Figure 2d), with weaker correlations between climate and tree growth for low than high competition-level trees ( $p=0.034$; mean $=0.10$ and 0.22 , respectively). However, different trends occurred in wet years (precipitation $>$ average): There was no significant difference between mean $r$-values for low and high competition-level trees (Figure $2 \mathrm{~d}, p=0.799$; mean $=0.15$ and 0.09 , respectively). For high competition-level trees, the mean correlation between precipitation and tree growth was higher in drought years than in wet years ( $p=0.023 ; r=0.22$ and 0.09 , respectively). For low competition-level trees, the differences between drought and wet years were no significant $(p=0.864 ; r=0.10$ and 0.15 , respectively).

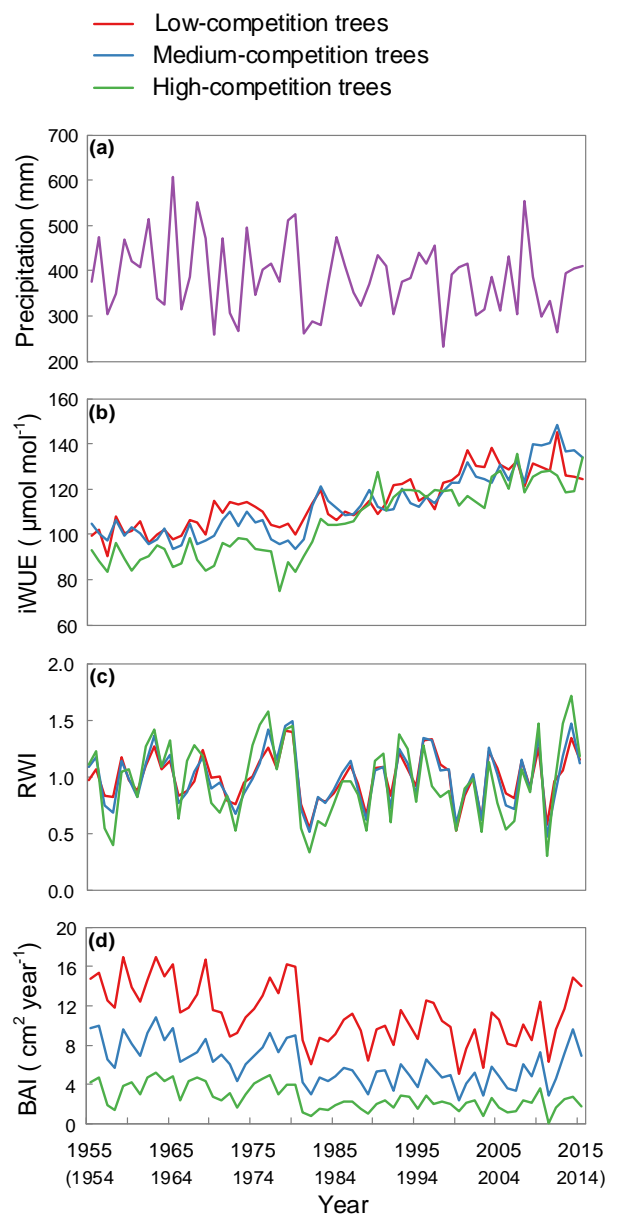

Figure 1. Trends in (a) precipitation and (b) intrinsic water-use efficiency ( $i W U E)(n=9)$ from 1954 to 2014 , and the (c) relative width index $(R W I)(n=82)$ and $(\mathbf{d})$ basal area increment $(B A I)(n=82)$ from 1955 to 2015. Raw data of $i W U E$ and tree-ring width in this study were derived from Lu et al. (2019).

Table 2. Summary of the linear mixed-effects model (LMM) of the relative width index (RWI) as a function of precipitation and individual tree $C I$ in 82 trees over the past 61 years.

\begin{tabular}{cccccc}
\hline Fixed Effects & Estimate & Std. Error & df & t-Value & $p$-Value \\
\hline (Intercept) & 0.6914 & 0.0470 & 4934 & 14.703 & $<0.0001$ \\
CI & -0.1472 & 0.0297 & 64 & -4.951 & $<\mathbf{0 . 0 0 0 1}$ \\
Precip & 0.0008 & 0.0001 & 4934 & 7.024 & $<0.0001$ \\
CI: Precip & 0.0003 & $7.37 \mathrm{e}-05$ & 4934 & 4.531 & $<\mathbf{0 . 0 0 0 1}$ \\
\hline
\end{tabular}



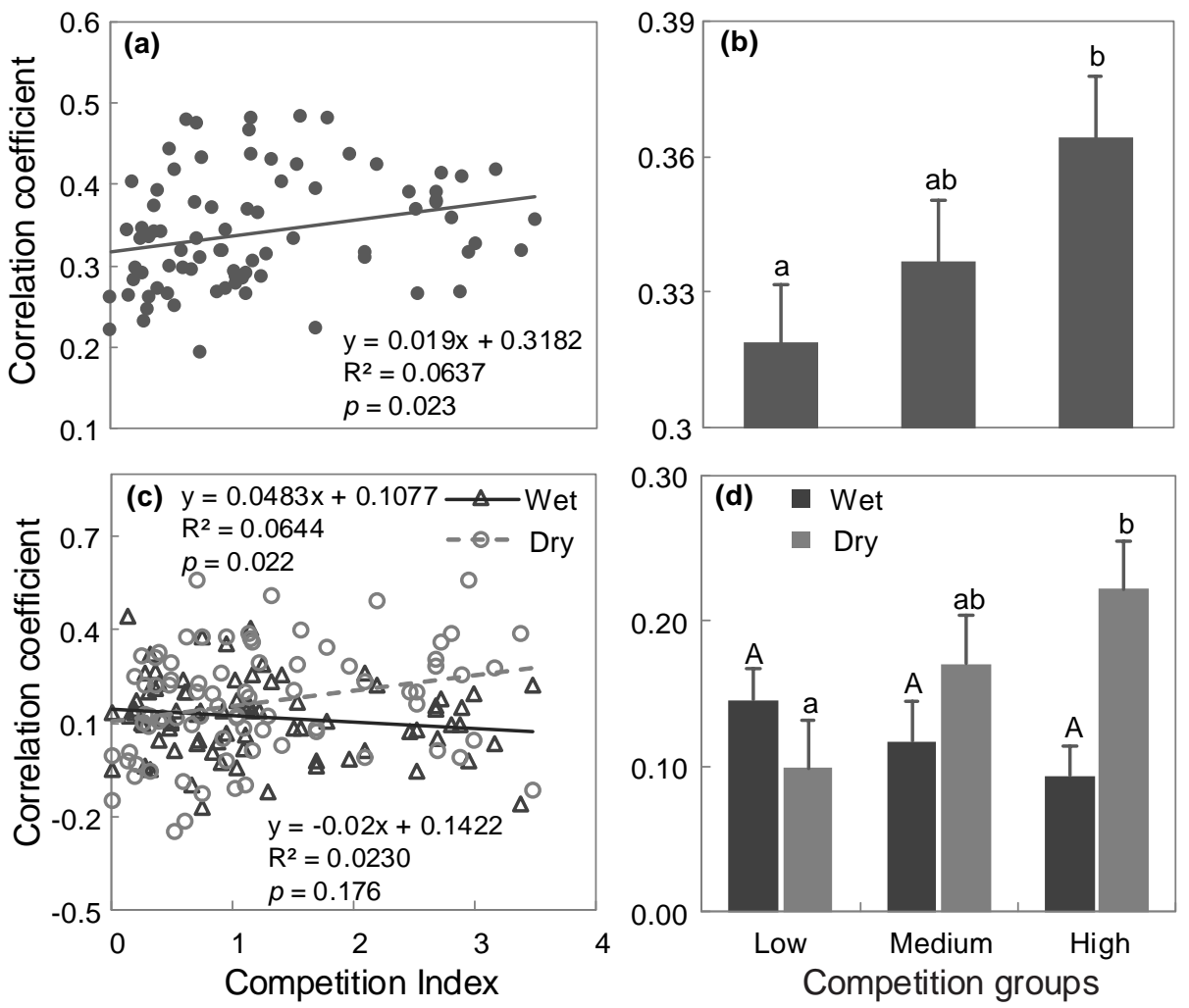

Figure 2. Linear regression $(n=82)$ between $C I$ and correlation coefficients $(r)$ for all the trees $(\mathbf{a}, \mathbf{c})$ and average correlation coefficients between precipitation and the RWI for low (SE; $n=27)$, medium (SE; $n=28$ ) and high (SE; $n=27)$ competition-level trees $(\mathbf{b}, \mathbf{d})$. Correlation coefficients were calculated for (a,b) all years (1955-2015), (c,d) 31 years with precipitation < average (dry years) and 30 years with precipitation $>$ average (wet years). Different letters indicate significant differences $(p<0.05)$ among tree competition groups.

Average trunk BAI and iWUE of all trees were $6.12 \mathrm{~cm}^{2}$ year ${ }^{-1}(\mathrm{SE}=0.31)$ and $110.00 \mu \mathrm{mol} \mathrm{mol}^{-1}$ $(\mathrm{SE}=1.33)$, respectively. Both the BAI $(p<0.001)$ and $i$ WUE $(p<0.001)$ were affected by competition. Thus, whether in all years, dry years or wet years, low competition-level trees had a larger $B A I$ (Figure 3), indicating that low competition-level trees may have a stronger overall carbon-fixation capacity. Meanwhile, the iWUE calculated from the alpha-cellulose of tree rings implied that low and medium competition-level trees had a higher iWUE than high-competition trees (Figure 4, upper panel), when all years are analyzed. These differences are the same when dry versus wet years are analyzed separately (Figure 4, lower panel), showing that trees with low competitive stress have an advantage in water use efficiency. When analyzing the impact of precipitation level on tree growth and intrinsic water use efficiency (Figure 5), we found that it was positive and negative, respectively, with significant differences among the different competition groups $(p<0.001$ for $B A I$ and $p=0.011$ for $i W U E$; Table 3). The BAI and iWUE of the high competition-level trees were more susceptible to precipitation than the low competition-level trees (absolute slope values of the high competition-level trees were greater than that of the low competition-level trees; Figure 5). 

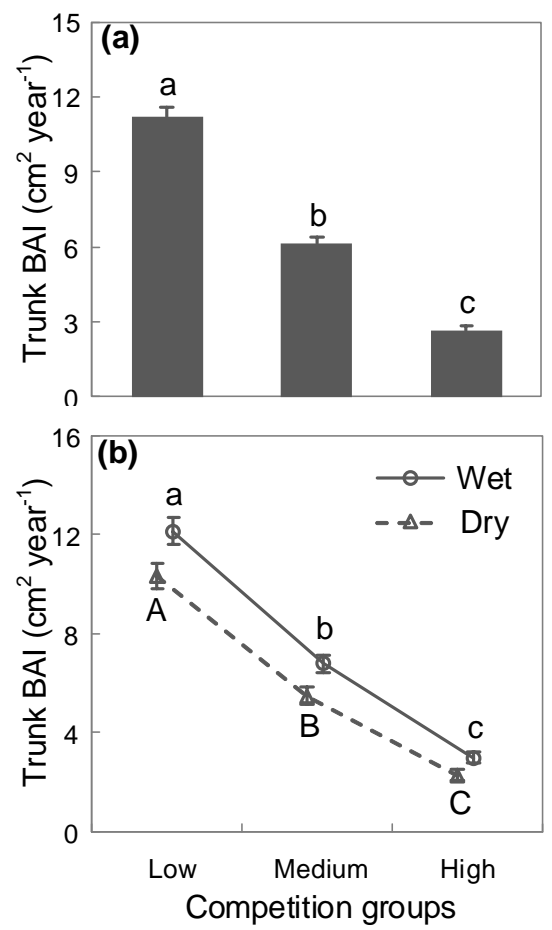

Figure 3. Average trunk BAI (SE) of different competition-level trees $(n=27,28$ and 27) for (a) all years (1955-2015), (b) 31 years with precipitation < average (dry years) and 30 years with precipitation $>$ average (wet years). Different letters indicate significant differences $(p<0.05)$ among tree competition groups.
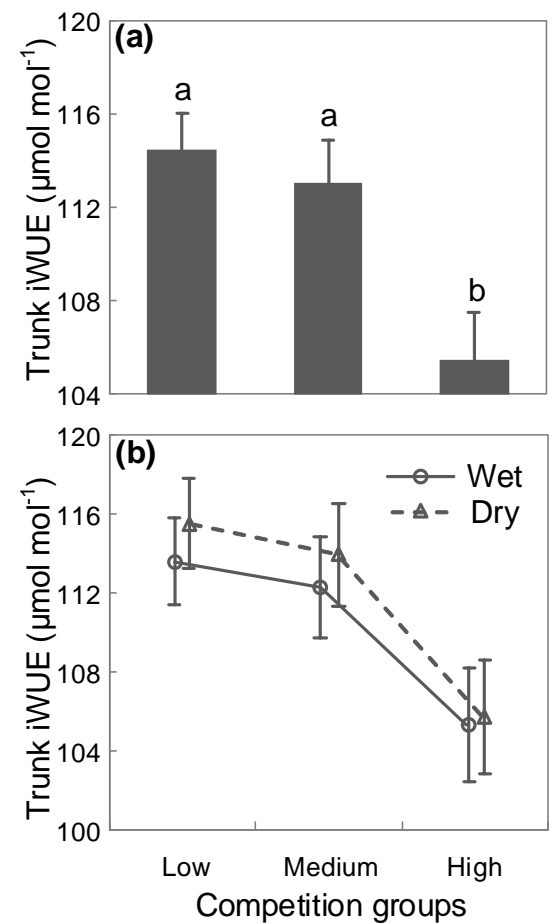

Figure 4. Average trunk $i W U E$ (SE) of different competition groups ( $n=3,3$, and 3 ) for (a) all years (1955-2015), (b) 31 years with precipitation < average (dry years) and 30 years with precipitation > average (wet years). Different letters indicate significant differences $(p<0.05)$ among tree competition groups. In dry years, the difference between low competition-level trees and high competition-level trees was significant at $90 \%$ confidence level $(p=0.083)$; in wet years, there was a significant difference between low and high competition-level trees at the $75 \%$ confidence level $(p=0.203)$. 
- Low-competition trees

- Medium-competition trees

- High-competition trees

- SMA regression of low-competition trees

- SMA regression of medium-competition trees

- SMA regression of high-competition trees
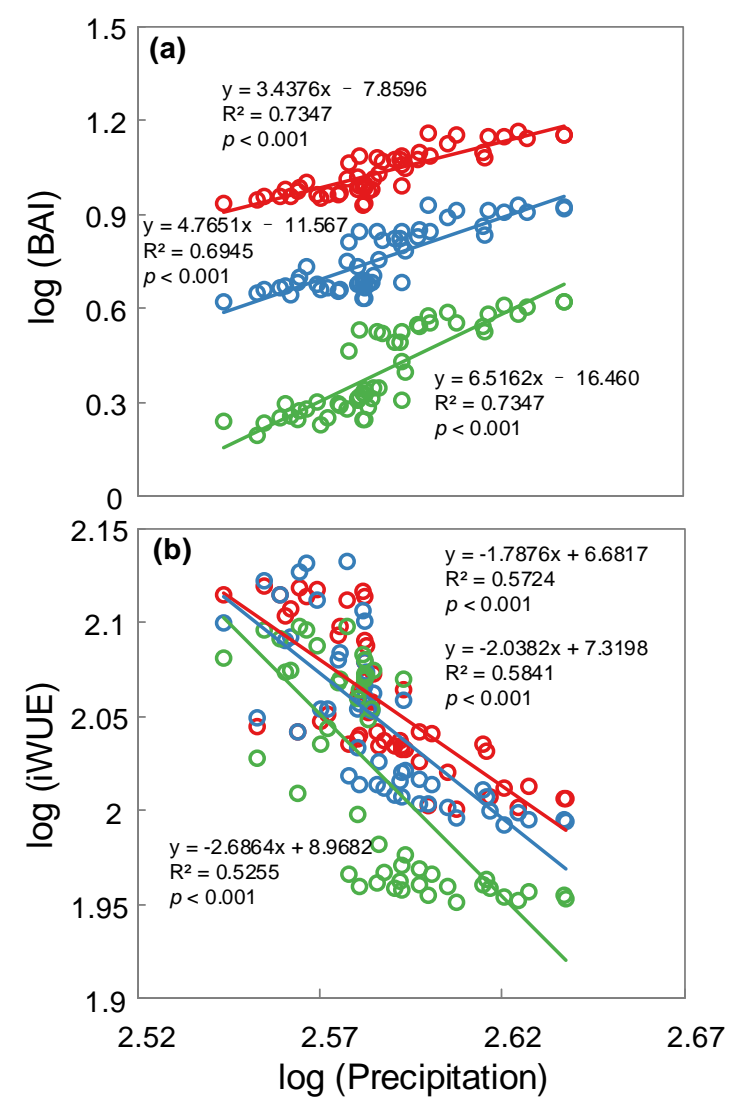

Figure 5. Relationships of 10-year moving average data over the past 61 years between (a) $B A I$ and precipitation ( $n=27,28$, and 27), and (b) $i W U E$ and precipitation ( $n=3,3$, and 3), for low, medium, and high competition-level trees, using standardized major axis (SMA) regression.

Table 3. Slope tests of the standardized major axis (SMA) regressions shown in Figure 5.

\begin{tabular}{cccc}
\hline Slope Test & Likelihood Ratio Statistic & df & $p$-Value \\
\hline$B A I$ and precipitation & 33.22 & 2 & $<\mathbf{0 . 0 0 0 1}$ \\
$i W U E$ and precipitation & 9.099 & 2 & $\mathbf{0 . 0 1 0 6}$ \\
\hline
\end{tabular}

Significant results are shown in bold, based on the null hypothesis. that slopes of the three SMA regressions are equal.

The SMA estimation and testing results showed that there was an allometric relationship between tree height and crown area (slope $>1$; Figure $6 \mathrm{a}$ and Table 4), as well as BAI (slope $>1$; Figure $6 \mathrm{~b}$ and Table 4). This indicated that the tree crown area and $B A I$ grew more proportionally than tree height. However, the same growth pattern was not observed between tree crown area and BAI (slope = 1; Figure $6 \mathrm{c}$ and Table 4). This indicated that the tree $B A I$ increased proportionally with tree crown area. 

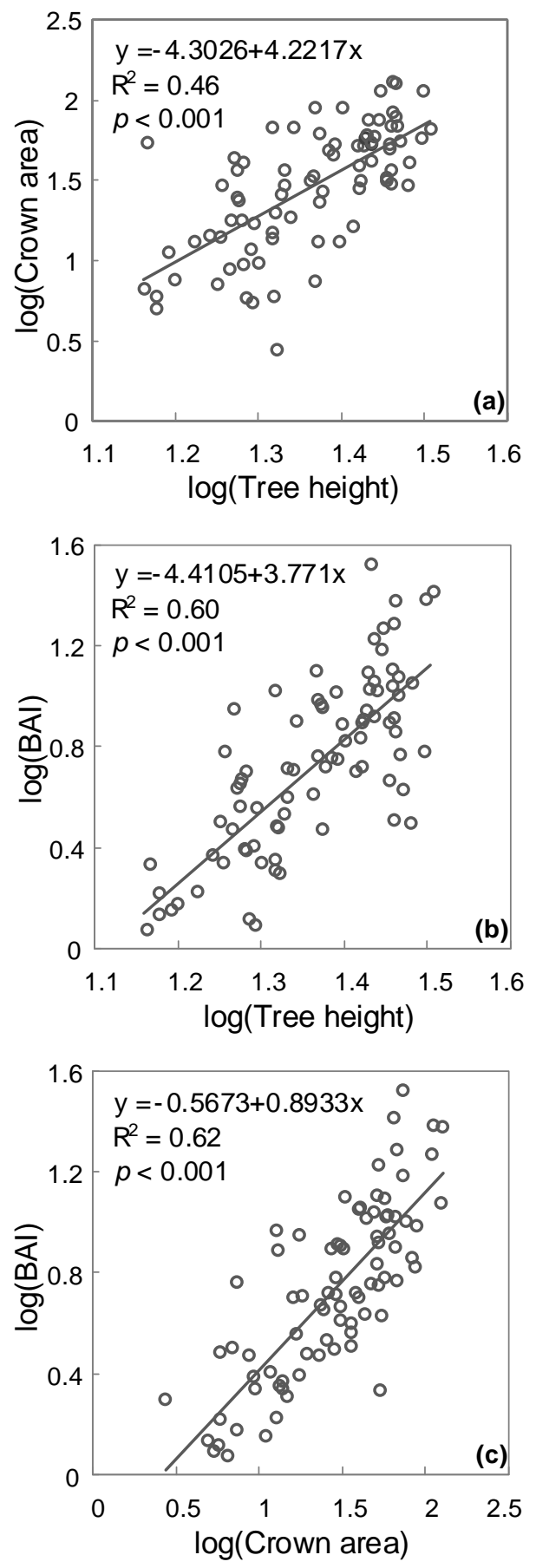

Figure 6. Allometric relationships $(n=82)$ between (a) tree height and crown area, (b) crown area and $B A I$, and (c) tree height and $B A I$, using SMA regression.

Table 4. Slope tests of the SMA regressions shown in Figure 6.

\begin{tabular}{cccc}
\hline Slope Test & Test Statistic & df & $p$-Value \\
\hline Tree height and crown area & 0.9365 & 80 & $<\mathbf{0 . 0 0 0 1}$ \\
Crown area and BAI & 0.9385 & 80 & $<\mathbf{0 . 0 0 0 1}$ \\
Tree height and BAI & -0.1794 & 60 & 0.1068
\end{tabular}

Significant results are shown in bold, based on the null hypothesis that the slope of the SMA regression is not different from one. 


\section{Discussion}

According to the SGH [4] and CSR plant strategy theory [5], in wet years (sufficient water resources) competition plays a significant role in regulating the relationship between tree growth and climate, while in dry years (water resource stress) tree growth response to climate is not subject to competition. Although our results showed that the interaction between competition and climate significantly affected tree growth (Table 2), the type of interaction was not the same as that predicted by the theoretical models but supported our hypothesis. High competition-level trees were more sensitive to climate variability than low competition-level trees in all years (Figure 2a,b), and particularly in the subset of years in which precipitation < average (dry years) (Figure 2c,d). However, in wet years (precipitation > average), there was no significant difference in the sensitivity of different competition-level tree's response to climate variability (Figure 2c,d). The inconsistency between the results and the theoretical models may be caused by the specific characteristics of the trees, which were not the same as short-lived species.

We assessed the ability of radial growth and water use efficiency of different competition-level trees. $B A I$ and $i W U E$ of the low competition-level trees were higher than those of the high competition-level trees at the trunk-level (Figures 3 and 4). This suggests that the increase in water use efficiency may promote the growth of low competition-level trees. Although the increase in tree height (Appendix A Figure A1c) increased the risk of water failure in low competition-level trees $[29,30]$, the increase in iWUE caused the low competition-level trees to be not disadvantaged by hydraulic limitation. Instead, the increase in tree height was likely disproportionately to increase the crown area (Figure 6a), which then might greatly increase the ability of low competition-level trees to fix carbon (Figure 6b). Therefore, in general, the ability of low competition-level trees to increase radial growth and utilize water is stronger than that of high competition-level trees.

As pointed out in other studies, an increase in height can enable plants to obtain more solar resources [26,27], and abundant solar resources can ultimately result in more photosynthetic products. When water and fertilizer in the soil limit plant growth, they can promote resource competition in the root system by distributing more biomass underground. Although previous studies have shown that plants compete symmetrically for water and fertilizer in the subsurface [50], there is currently much evidence that competition between plant roots is asymmetric or inclined to be asymmetric [51-54]. The degree of asymmetry in competition can increase with increasing water stress gradients [52]. In addition, trees are perennial plants. The existence of an interannual carbon distribution means their growth is not only affected by carbon fixation in the current year, but also by the growth of the previous years [33]. This is also confirmed in our previous study on the P. wilsonii in this region [38]. Even in extreme weather conditions, tree growth calls upon carbon stored more than a decade ago $[55,56]$. The greater ability to grow of low competition-level trees caused by asymmetric competition (Figure $6 \mathrm{~b}$ ), as well as the nutrients stored in the carbon pool from previous years, offers reserves that can be used under harsh weather conditions, theoretically ensuring that low competition-level trees cope better with climate variability than high competition-level trees, thus showing a lower sensitivity to climate variability [22], as it was observed in this study.

Our results regarding tree radial growth and water use efficiency showed that the absolute value of slopes of the SMA regression analysis between BAI and precipitation and $i W U E$ and precipitation gradually increased with increasing competition stress in all years (Figure $5 \mathrm{a}, \mathrm{b}$; Table 3 ). When water stress increased, high competition-level trees responded to environment changes by increasing their iWUE more quickly. However, BAI also dropped more rapidly, suggesting that the elevation of $i W U E$ in high competition-level trees could not counter the negative effects of drought on tree growth (i.e., when the degree of drought increased, trees suffering from highly competitive stress would be more susceptible). Thus, high competition-level trees were more sensitive to climate variability in the subset of years that was dry than that of wet years (Figure 2c,d). Although, in dry and wet years, the slope of the SMA regression between $i W U E$ and precipitation has no significant difference between different competition-level trees (Appendix A Figure A2c,d; Appendix A Table A1), it has a significant 
difference in all years (Figure 5b; Table 3) at least indicates that the above rules exist between different precipitation levels (i.e., during the transition from dry to wet years).

Although the SGH and CSR plant strategy theory have extensive experimental support, their premise is that the competing species (or competing individuals of the same species) have different ecological strategies (competition or stress tolerance) [10,57]. In real situations, the strategies of competing species are more complicated [57], and the nature of the stress gradient will also affect the interaction [58]. Therefore, many studies present results that contradict the prediction of the models for the same ecosystem [59,60]. According to Mastre et al.'s (2009) refinement of the SGH [57], if two competing species occupy the same niche (to generalize to the intraspecific level is that different competitive individuals have the same niche), mutual benefit is unlikely to occur when abiotic stress reduces their growth $[61,62]$. Even if the two species (or the two individuals of the same species) have displayed a trend of mutual benefit under an adverse environment, they cannot counter the negative impact of resource competition as the competition intensifies. In addition, the study by Lin et al. (2012) in self-thinning plants shows that, under adverse conditions, symmetric competition promotes tree growth (supporting SGH), while asymmetric competition will increase the abiotic stress of trees (contradictory with SGH but in support of our research) [63].

Our study results in mature trees suggested that competition has a larger effect on climate-growth relationship in relatively drought years. However, there were also some studies in mature trees supporting that the effect of competition was obviously weaker in drought years [64-66]. Considering the results of competition in mediating the climate-growth relationship can be species- and context-specific [67], our study here provides additional instance for individual tree growth models. In this study, we performed the research in a pure forest under natural (non-managed) conditions. And the competition we concerned here is the inhibitory impact of plants on the ability of other plants to capture resources (competitive mechanism), which is not the whole mechanism that plants restrain the fitness of neighbors through changing their environment [5]. In this sense, our research has the same meaning for intraspecific and interspecific competition $[10,68]$. Thus, our focus on intraspecific competition here can also be extended to the interspecific level [63]. However, our competition in this study was based on a comprehensive consideration of the situation of the surrounding competitors and the size of the target trees themselves, and did not distinguish between the neighborhood effects and the impact of the target tree size on the competition [69]. We recommend a more in-depth discussion of this in future research.

\section{Conclusions}

Our results show that high competition-level trees display larger physiological stress. Both the tree radial growth and water-use efficiency of high competition-level trees are lower than those of low competition-level trees. As a consequence, high competition-level trees are more sensitive to climate variation in all years. When the degree of drought increases, high competition-level trees compensate for its competitive disadvantages by improving the water-use efficiency more rapidly, but they cannot change the fact that the radial growth drops sharply. Ultimately, the increase in drought will further increase the physiological stress of high competition-level trees. This makes high competition-level trees still more sensitive to climate variability in the subset of years that is relatively drought (precipitation < average). However, in relatively wet years (precipitation $>$ average), there is no significant difference between the sensitivity of different competition-level trees in response to climate, indicating that competition plays a less important role in regulating the climate-growth relationship. Our focus on the different competition-level trees response to climate variability in semi-arid regions has important implications for tree growth models at the individual level, and is of importance for forest management strategies under climate change.

Author Contributions: C.Z. (Changming Zhao) and K.L. conceived and designed the experiments. K.L., C.Z. (Cankun Zhang) and X.D. performed the experiments. K.L. analyzed the data. K.L. wrote the manuscript; N.C., C.Z. (Changming Zhao), C.Z. (Cankun Zhang) and X.D. provided editorial advice. 
Funding: This research was funded by the Strategic Priority Research Program of Chinese Academy of Sciences (XDA20100101), the National Natural Science Foundation of China (31522013) and Major Special Science and Technology Project of Gansu Province (18ZD2FA009). The APC was funded by the National Natural Science Foundation of China (31522013).

Acknowledgments: We thank the editor and two anonymous reviewers for their helpful comments and suggestions.

Conflicts of Interest: The authors declare no conflict of interest.

\section{Appendix A}
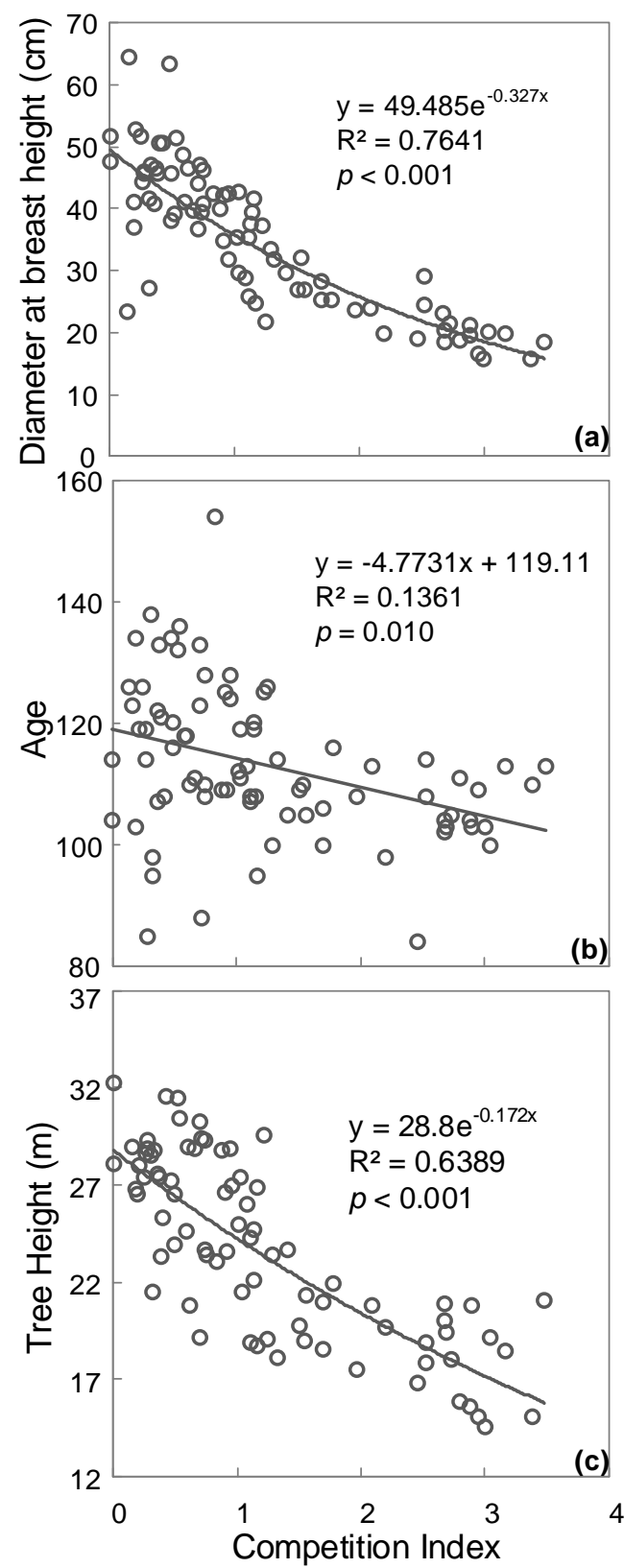

Figure A1. Negative exponential regression $(n=82)$ between $(\mathbf{a})$ individual tree competition index $(C I)$ and diameter at breast height $(\mathrm{DBH}),(\mathrm{c})$ individual tree $C I$ and tree height. Linear regression $(n=82)$ between $(\mathbf{b})$ individual tree $C I$ and tree age. 
- SMA regression of low-competition trees

$\rightarrow$ SMA regression of high-competition trees

$\rightarrow$ SMA regression of medium-competition trees
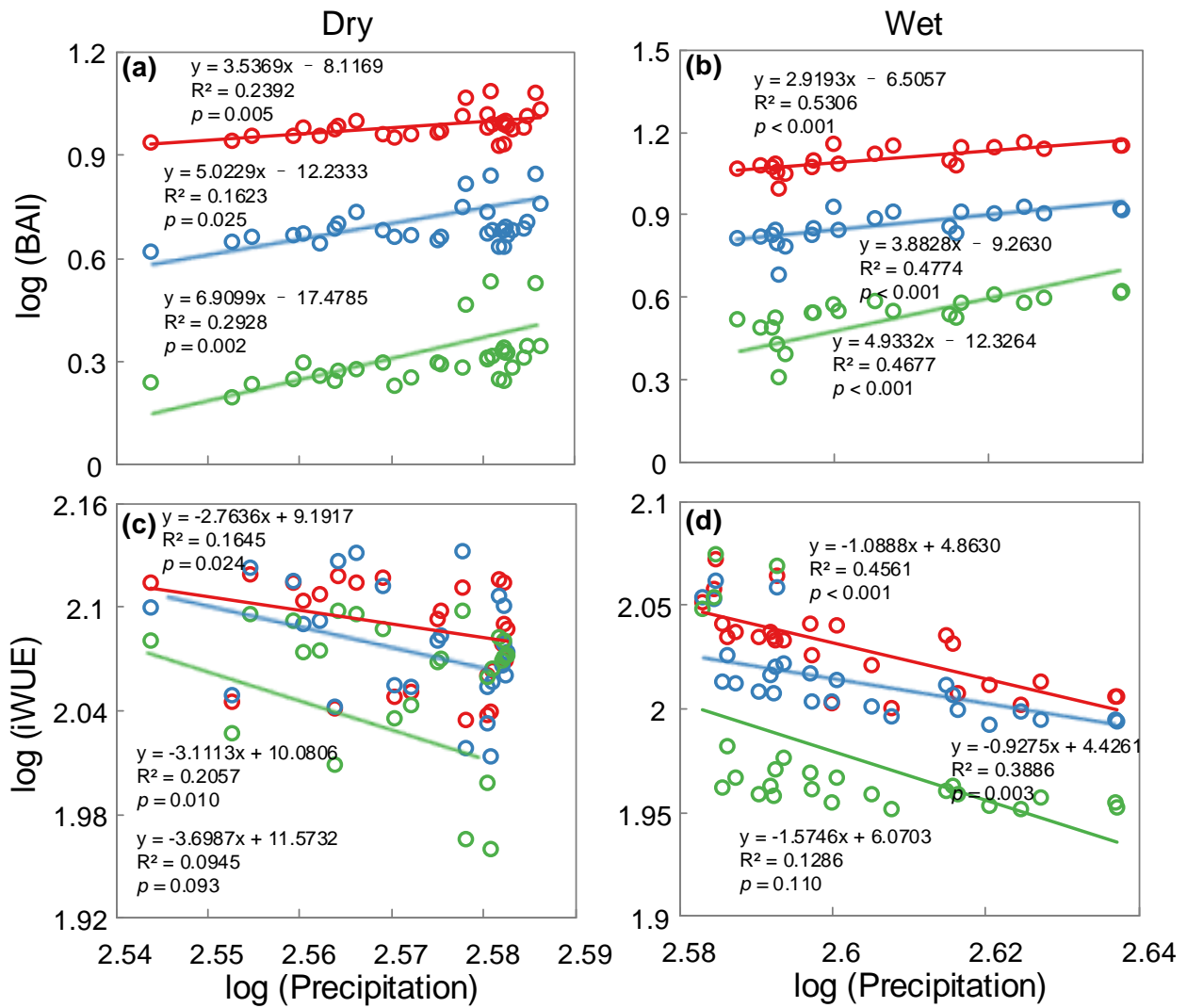

Figure A2. Relationships of 10-year moving average data of the relatively dry and wet years over the past 61 years between $(\mathbf{a}, \mathbf{b})$ basal area increment $(B A I)$ and precipitation $(n=27,28$, and 27), and (c,d) intrinsic water use efficiency (iWUE) and precipitation $(n=3,3$ and 3), for low, medium and high competition-level trees, using standardized major axis (SMA) regression.

Table A1. Slope tests of the SMA regressions shown in Figure A2.

\begin{tabular}{ccccc}
\hline Precipitation Level & Slope Test & Likelihood Ratio Statistic & df & $p$-Value \\
\hline Dry & $B A I$ and precipitation & 8.389 & 2 & $\mathbf{0 . 0 1 5 1}$ \\
Wet & $B A I$ and precipitation & 4.902 & 2 & 0.0862 \\
Dry & $i W U E$ and precipitation & 1.394 & 2 & 0.4981 \\
Wet & $i W U E$ and precipitation & 3.482 & 2 & 0.1753
\end{tabular}

Significant results are shown in bold, based on the null hypothesis. that slopes of the three SMA regressions are equal.

\section{References}

1. Greenlee, J.T.; Callaway, R.M. Abiotic stress and the relative importance of interference and facilitation in montane bunchgrass communities in western Montana. Am. Nat. 1996, 148, 386-396. [CrossRef]

2. Dunnett, N.; Grime, J. Competition as an amplifier of short-term vegetation responses to climate: An experimental test. Funct. Ecol. 1999, 13, 388-395. [CrossRef]

3. Kikvidze, Z.; Khetsuriani, L.; Kikodze, D.; Callaway, R.M. Seasonal shifts in competition and facilitation in subalpine plant communities of the central Caucasus. J. Veg. Sci. 2006, 17, 77-82. [CrossRef]

4. Bertness, M.D.; Callaway, R. Positive interactions in communities. Trends Ecol. Evol. 1994, 9, $191-193$. [CrossRef] 
5. Grime, J.P. Plant Strategies, Vegetation Processes, and Ecosystem Properties; John Wiley \& Sons: Hoboken, NJ, USA, 2006.

6. Tilman, D. Plant Strategies and the Dynamics and Structure of Plant Communities; Princeton University Press: Princeton, NJ, USA, 1988; p. 359.

7. Callaway, R.M. Positive Interactions and Interdependence in Plant Communities; Springer: Dordrecht, The Netherlands, 2007.

8. Chu, C.J.; Weiner, J.; Maestre, F.T.; Xiao, S.; Wang, Y.S.; Li, Q.; Yuan, J.L.; Zhao, L.Q.; Ren, Z.W.; Wang, G. Positive interactions can increase size inequality in plant populations. J. Ecol. 2009, 97, 1401-1407. [CrossRef]

9. McIntire, E.J.B.; Fajardo, A. Facilitation within species: A possible origin of group-selected superorganisms. Am. Nat. 2011, 178, 88-97. [CrossRef] [PubMed]

10. Carnwath, G.C.; Nelson, C.R. The effect of competition on responses to drought and interannual climate variability of a dominant conifer tree of western North America. J. Ecol. 2016, 104, 1421-1431. [CrossRef]

11. Via, S.; Gomulkiewicz, R.; De Jong, G.; Scheiner, S.M.; Schlichting, C.D.; Van Tienderen, P.H. Adaptive phenotypic plasticity: Consensus and controversy. Trends Ecol. Evol. 1995, 10, 212-217. [CrossRef]

12. Awad, H.; Barigah, T.; Badel, E.; Cochard, H.; Herbette, S. Poplar vulnerability to xylem cavitation acclimates to drier soil conditions. Physiol. Plant. 2010, 139, 280-288. [CrossRef] [PubMed]

13. Woods, K.D. Living long by staying small: Stem layering as an adaptive life-history trait in shade-tolerant tree seedlings. Can. J. For. Res. 2008, 38, 480-487. [CrossRef]

14. Barnard, D.M.; Meinzer, F.C.; Lachenbruch, B.; McCulloh, K.A.; Johnson, D.M.; Woodruff, D.R. Climate-related trends in sapwood biophysical properties in two conifers: Avoidance of hydraulic dysfunction through coordinated adjustments in xylem efficiency, safety and capacitance. Plant Cell Environ. 2011, 34, 643-654. [CrossRef] [PubMed]

15. Pedersen, B.S. The role of stress in the mortality of midwestern oaks as indicated by growth prior to death. Ecology 1998, 79, 79-93. [CrossRef]

16. Ogle, K.; Whitham, T.G.; Cobb, N.S. Tree-ring variation in pinyon predicts likelihood of death following severe drought. Ecology 2000, 81, 3237-3243. [CrossRef]

17. Suarez, M.L.; Ghermandi, L.; Kitzberger, T. Factors predisposing episodic drought-induced tree mortality in Nothofagus-site, climatic sensitivity and growth trends. J. Ecol. 2004, 92, 954-966. [CrossRef]

18. McDowell, N.G.; Allen, C.D.; Marshall, L. Growth, carbon-isotope discrimination, and drought-associated mortality across a Pinus ponderosa elevational transect. Glob. Change Biol. 2010, 16, 399-415. [CrossRef]

19. Sánchez-Salguero, R.; Linares, J.C.; Camarero, J.J.; Madrigal-González, J.; Hevia, A.; Sánchez-Miranda, Á.; Ballesteros-Cánovas, J.A.; Alfaro-Sánchez, R.; García-Cervigón, A.I.; Bigler, C. Disentangling the effects of competition and climate on individual tree growth: A retrospective and dynamic approach in Scots pine. For. Ecol. Manag. 2015, 358, 12-25. [CrossRef]

20. Mérian, P.; Lebourgeois, F. Size-mediated climate-growth relationships in temperate forests: A multi-species analysis. For. Ecol. Manag. 2011, 261, 1382-1391. [CrossRef]

21. Bennett, A.C.; McDowell, N.G.; Allen, C.D.; Anderson-Teixeira, K.J. Larger trees suffer most during drought in forests worldwide. Nat. Plants 2015, 1, 15139. [CrossRef]

22. Giardina, F.; Konings, A.G.; Kennedy, D.; Alemohammad, S.H.; Oliveira, R.S.; Uriarte, M.; Gentine, P. Tall Amazonian forests are less sensitive to precipitation variability. Nat. Geosci. 2018, 11, 405. [CrossRef]

23. Rozas, V.; DeSoto, L.; Olano, J.M. Sex-specific, age-dependent sensitivity of tree-ring growth to climate in the dioecious tree Juniperus thurifera. New Phytol. 2009, 182, 687-697. [CrossRef]

24. Vieira, J.; Campelo, F.; Nabais, C. Age-dependent responses of tree-ring growth and intra-annual density fluctuations of Pinus pinaster to Mediterranean climate. Trees 2009, 23, 257-265. [CrossRef]

25. Getzin, S.; Worbes, M.; Wiegand, T.; Wiegand, K. Size dominance regulates tree spacing more than competition within height classes in tropical Cameroon. J. Trop. Ecol. 2011, 27, 93-102. [CrossRef]

26. Weiner, J.; Thomas, S.C. Size variability and competition in plant monocultures. Oikos 1986, 47, $211-222$. [CrossRef]

27. Connolly, J.; Wayne, P. Asymmetric competition between plant species. Oecologia 1996, 108, 311-320. [CrossRef] [PubMed]

28. Martínez-Vilalta, J.; Cochard, H.; Mencuccini, M.; Sterck, F.; Herrero, A.; Korhonen, J.; Llorens, P.; Nikinmaa, E.; Nole, A.; Poyatos, R. Hydraulic adjustment of Scots pine across Europe. New Phytol. 2009, 184, 353-364. [CrossRef] [PubMed] 
29. Koch, G.W.; Sillett, S.C.; Jennings, G.M.; Davis, S.D. The limits to tree height. Nature 2004, 428, 851. [CrossRef] [PubMed]

30. Ryan, M.G.; Yoder, B.J. Hydraulic limits to tree height and tree growth. Bioscience 1997, 47, 235-242. [CrossRef]

31. Clark, D.A.; Brown, S.; Kicklighter, D.W.; Chambers, J.Q.; Thomlinson, J.R.; Ni, J. Measuring net primary production in forests: Concepts and field methods. Ecol. Appl. 2001, 11, 356-370. [CrossRef]

32. Fernández-de-Uña, L.; McDowell, N.G.; Canellas, I.; Gea-Izquierdo, G. Disentangling the effect of competition, $\mathrm{CO}_{2}$ and climate on intrinsic water-use efficiency and tree growth. J. Ecol. 2016, 104, 678-690. [CrossRef]

33. Anderegg, W.R.; Schwalm, C.; Biondi, F.; Camarero, J.J.; Koch, G.; Litvak, M.; Ogle, K.; Shaw, J.D.; Shevliakova, E.; Williams, A. Pervasive drought legacies in forest ecosystems and their implications for carbon cycle models. Science 2015, 349, 528-532. [CrossRef]

34. Biondi, F.; Qeadan, F. A theory-driven approach to tree-ring standardization: Defining the biological trend from expected basal area increment. Tree Ring Res. 2008, 64, 81-96. [CrossRef]

35. Vaganov, E.A.; Hughes, M.K.; Shashkin, A.V. Growth Dynamics of Conifer Tree Rings: Images of Past and Future Environments; Springer Science \& Business Media: Berlin, Germany, 2006; Volume 183.

36. Ciais, P.; Sabine, C.; Bala, G.; Bopp, L.; Brovkin, V.; Canadell, J.; Chhabra, A.; DeFries, R.; Galloway, J.; Heimann, M. Carbon and other biogeochemical cycles. In Climate Change 2013: The Physical Science Basis. Contribution of Working Group I to the Fifth Assessment Report of the Intergovernmental Panel on Climate Change; Cambridge University Press: Cambridge, UK, 2014; pp. 465-570.

37. Jump, A.S.; Hunt, J.M.; Penuelas, J. Rapid climate change-related growth decline at the southern range edge of Fagus sylvatica. Glob. Change Biol. 2006, 12, 2163-2174. [CrossRef]

38. Lu, K.; Chen, N.; Zhang, X.; Wang, J.; Wang, M.; Khan, S.; Han, C.; Zhang, C.; Wang, S.; Wang, L.; et al. Increased drought and atmospheric $\mathrm{CO}_{2}$ positively impact intrinsic water use efficiency but do not promote tree growth in semi-arid areas of northwestern China. Trees Struct Funct. 2019, 33, 669-679. [CrossRef]

39. McCarroll, D.; Loader, N.J. Stable isotopes in tree rings. Quat. Sci. Rev. 2004, 23, 771-801. [CrossRef]

40. Hegyi, F. A Simulation Model for Managing Jack-Pine Standssimulation; Royal College of Forestry: Stockholm, Sweden, 1974; pp. 74-90.

41. LeBlanc, D.C. Relationships between breast-height and whole-stem growth indices for red spruce on Whiteface Mountain, New York. Can. J. For. Res. 1990, 20, 1399-1407. [CrossRef]

42. R Development Core Team. R: A Language and Environment for Statistical Computing; R. Development Core Team: Vienna, Austria, 2016.

43. Bunn, A.G. A dendrochronology program library in R (dplR). Dendrochronologia 2008, 26, 115-124. [CrossRef]

44. Brendel, O.; Iannetta, P.P.M.; Stewart, D. A rapid and simple method to isolate pure alpha-cellulose. Phytochem. Anal. 2000, 11, 7-10. [CrossRef]

45. Evans, M.N.; Schrag, D.P. A stable isotope-based approach to tropical dendroclimatology. Geochim. Cosmochim. Acta 2004, 68, 3295-3305. [CrossRef]

46. Gaudinski, J.B.; Dawson, T.E.; Quideau, S.; Schuur, E.A.; Roden, J.S.; Trumbore, S.E.; Sandquist, D.R.; Oh, S.-W.; Wasylishen, R.E. Comparative analysis of cellulose preparation techniques for use with ${ }^{13} \mathrm{C},{ }^{14} \mathrm{C}$, and ${ }^{18} \mathrm{O}$ isotopic measurements. Anal. Chem. 2005, 77, 7212-7224. [CrossRef]

47. Chen, T.; Qin, D.; Li, J. Response of $\mathrm{CO}_{2}$ concentration parameters and water-use efficiency derived from tree-ring $13 \mathrm{C}$ series to atmospheric $\mathrm{CO}_{2}$ increase. J. Glaciol. Geocryol. 2001, 23, 41-45.

48. Farquhar, G.D.; O'Leary, M.H.; Berry, J.A. On the relationship between carbon isotope discrimination and the intercellular carbon dioxide concentration in leaves. Funct. Plant Biol. 1982, 9, 121-137. [CrossRef]

49. Farquhar, G.D.; Ehleringer, J.R.; Hubick, K.T. Carbon isotope discrimination and photosynthesis. Annu. Rev. Plant Biol. 1989, 40, 503-537. [CrossRef]

50. Bolte, A.; Villanueva, I. Interspecific competition impacts on the morphology and distribution of fine roots in European beech (Fagus sylvatica L.) and Norway spruce (Picea abies (L.) Karst.). Eur. J. For. Res. 2006, 125, 15-26. [CrossRef]

51. Rajaniemi, T.K. Evidence for size asymmetry of belowground competition. Basic Appl. Ecol. 2003, 4, $239-247$. [CrossRef]

52. Rewald, B.; Leuschner, C. Does root competition asymmetry increase with water availability? Plant Ecol. Divers. 2009, 2, 255-264. [CrossRef]

53. Lei, P.; Scherer-Lorenzen, M.; Bauhus, J. Belowground facilitation and competition in young tree species mixtures. For. Ecol. Manag. 2012, 265, 191-200. [CrossRef] 
54. Weremijewicz, J.; Janos, D.P. Common mycorrhizal networks amplify size inequality in Andropogon gerardii monocultures. New Phytol. 2013, 198, 203-213. [CrossRef] [PubMed]

55. Richardson, A.D.; Carbone, M.S.; Keenan, T.F.; Czimczik, C.I.; Hollinger, D.Y.; Murakami, P.; Schaberg, P.G.; $\mathrm{Xu}, \mathrm{X}$. Seasonal dynamics and age of stemwood nonstructural carbohydrates in temperate forest trees. New Phytol. 2013, 197, 850-861. [CrossRef]

56. Locosselli, G.M.; Buckeridge, M.S. Dendrobiochemistry, a missing link to further understand carbon allocation during growth and decline of trees. Trees Struct Funct. 2017, 31, 1745-1758. [CrossRef]

57. Maestre, F.T.; Callaway, R.M.; Valladares, F.; Lortie, C.J. Refining the stress-gradient hypothesis for competition and facilitation in plant communities. J. Ecol. 2009, 97, 199-205. [CrossRef]

58. Kawai, T.; Tokeshi, M. Testing the facilitation-competition paradigm under the stress-gradient hypothesis: Decoupling multiple stress factors. Proc. R. Soc. B Biol. Sci. 2007, 274, 2503. [CrossRef] [PubMed]

59. Tielbörger, K.; Kadmon, R. Temporal environmental variation tips the balance between facilitation and interference in desert plants. Ecology 2000, 81, 1544-1553. [CrossRef]

60. Holzapfel, C.; Tielbörger, K.; Parag, H.A.; Kigel, J.; Sternberg, M. Annual plant-shrub interactions along an aridity gradient. Basic Appl. Ecol. 2006, 7, 268-279. [CrossRef]

61. Carrick, P.J. Competitive and facilitative relationships among three shrub species, and the role of browsing intensity and rooting depth in the Succulent Karoo, South Africa. J. Veg. Sci. 2003, 14, 761-772. [CrossRef]

62. Ludwig, F.; Dawson, T.; Prins, H.; Berendse, F.; De Kroon, H. Below-ground competition between trees and grasses may overwhelm the facilitative effects of hydraulic lift. Ecol. Lett. 2004, 7, 623-631. [CrossRef]

63. Lin, Y.; Berger, U.; Grimm, V.; Ji, Q.-R. Differences between symmetric and asymmetric facilitation matter: Exploring the interplay between modes of positive and negative plant interactions. J. Ecol. 2012, 100, 1482-1491. [CrossRef]

64. Linares, J.C.; Camarero, J.J.; Carreira, J.A. Plastic responses of Abies pinsapo xylogenesis to drought and competition. Tree Physiol. 2009, 29, 1525-1536. [CrossRef]

65. Kolb, T.E.; Agee, J.; Fule, P.Z.; McDowell, N.; Pearson, K.; Sala, A.; Waring, R. Perpetuating old ponderosa pine. For. Ecol. Manag. 2007, 249, 141-157. [CrossRef]

66. Kunstler, G.; Albert, C.H.; Courbaud, B.; Lavergne, S.; Thuiller, W.; Vieilledent, G.; Zimmermann, N.E.; Coomes, D.A. Effects of competition on tree radial-growth vary in importance but not in intensity along climatic gradients. J. Ecol. 2011, 99, 300-312. [CrossRef]

67. Coates, K.D.; Lilles, E.B.; Astrup, R. Competitive interactions across a soil fertility gradient in a multispecies forest. J. Ecol. 2013, 101, 806-818. [CrossRef]

68. Begon, M.; Townsend, C.R.; Harper, J.L. Ecology: From Individuals to Ecosystems, 4th ed.; Blackwell: Oxford, UK, 2006.

69. Gómez-Aparicio, L.; García-Valdés, R.; Ruíz-Benito, P.; Zavala, M.A. Disentangling the relative importance of climate, size and competition on tree growth in Iberian forests: Implications for forest management under global change. Glob. Change Biol. 2011, 17, 2400-2414. [CrossRef]

(C) 2019 by the authors. Licensee MDPI, Basel, Switzerland. This article is an open access article distributed under the terms and conditions of the Creative Commons Attribution (CC BY) license (http://creativecommons.org/licenses/by/4.0/). 